\title{
Práticas de gestão do conhecimento em grupos de pesquisa da rede Instituto Fábrica do Milênio
}

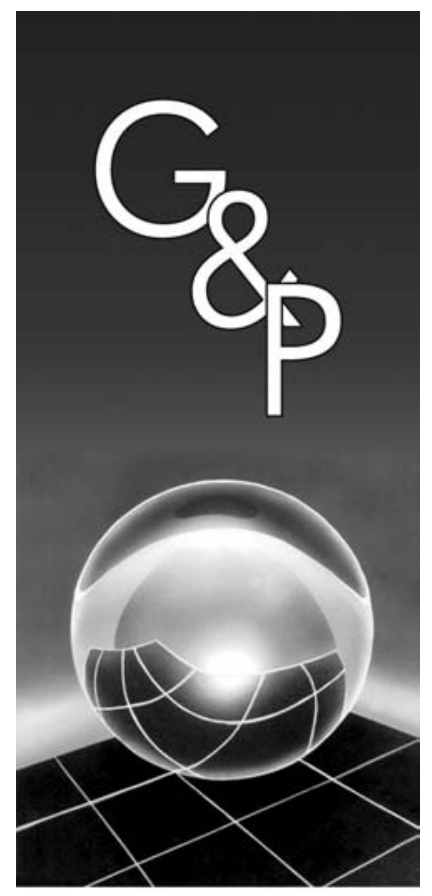

\author{
Karina Kühl de Lima \\ Daniel Capaldo Amaral
}

\begin{abstract}
Resumo
Nos últimos anos houve um crescimento dos programas de pesquisa em rede, em que diferentes grupos de pesquisa reúnem competências em busca de avanços tecnológicos significativos. A gestão do conhecimento $(G C)$ é um aspecto fundamental nessas iniciativas. Este trabalho descreve as práticas de GC em grupos de pesquisa membros de uma rede de âmbito nacional, o IFM. Identifica melhores práticas e discute desafios para a sua implantação. Empregou-se o estudo de casos múltiplos, por meio de entrevistas em profundidade, aplicadas a uma amostra de grupos de pesquisa da rede. Como resultado, apresenta-se um modelo de processo de desenvolvimento de pesquisa, um modelo teórico de práticas de GC em grupos de pesquisa, a lista de melhores práticas de GC identificadas e os desafios enfrentados pelos grupos na introdução das práticas. O resultado indica o uso de poucas práticas sistematizadas e predomínio da conversão do tipo socialização (tácito-tácito). Indica, portanto, que há potencial para o desenvolvimento de metodologias e ferramentas de GC voltadas especificamente para essa classe de organizações.
\end{abstract}

Palavras-chave: Gestão do conhecimento. Portais corporativos. Grupos de pesquisa. Redes de pesquisa.

\section{Introdução}

A complexidade das novas tecnologias exige um esforço cada vez maior das empresas e instituições de pesquisa. Os produtos ou patentes atuais dependem da união de esforços de especialistas de diferentes áreas do conhecimento. A solução é a cooperação entre diferentes tipos de organizações, sejam elas localizadas em universidades, institutos ou empresas privadas.

Atentos a essa questão, governos, instituições de apoio à pesquisa, empresas e os próprios pesquisadores vêm incentivando e valorizando a formação de redes de pesquisa. Elas são uma maneira de unir esforços com o intuito de compartilhar recursos físicos, conhecimentos e competências (CANONGIA et al., 2004).

Há vários exemplos de redes de pesquisa sendo criadas e fomentadas por diferentes atores. A comunidade européia, por força da sua agência de pesquisa, vem incentivando projetos desenvolvidos por consórcios, contendo grupos de pesquisa, empresas e institutos. A base de dados (CORDIS, 2007) contém vários exemplos. No Brasil, cita-se: Projeto Genoma Nacional; Rede de Pesquisa em Nanobiotecnologia (DURAN; AZEVEDO, 2002); e Rede de Pesquisa em Sistemas Produtivos e Inovativos Locais (REDESIST, 2004).
Mesmo as empresas voltadas para a inovação tecnológica estão atentas a este esforço. Huston e Sakkab (2006) apresentam o caso da empresa Procter e Gamble que está criando comunidades para fomentar redes de pesquisa entre os seus laboratórios de $\mathrm{P} \& \mathrm{D}$ e diferentes atores: grupos de pesquisa em universidades, institutos de pesquisa privados, fornecedores e clientes. Esta integração é reconhecida em muitas disciplinas, do marketing, da aprendizagem organizacional e outras, como o pilar para uma estratégia competitiva baseada em inovação (SANTOS, 2003).

Liyanage et al. (1999) discorrem sobre o assunto. Eles apresentam o conceito de gestão da pesquisa e sua evolução histórica. Demonstram que o desafio atual é o de gerenciar a pesquisa em estreita ligação com o mercado, envolvendo várias instituições da sociedade. Demonstram a relevância, mas não as práticas de como executá-lo.

Um dos problemas é que, embora produtoras de conhecimento, as organizações e instituições de pesquisa nem sempre conseguem registrar adequadamente o conhecimento gerado e difundi-lo interna e externamente. As iniciativas na área de gestão do conhecimento são uma 
solução promissora. Elas podem apoiar esse processo, mas não foram encontradas pesquisas sobre a aplicação de métodos e técnicas de GC especificamente em grupos de pesquisa, principalmente considerando o contexto das redes.

Um primeiro passo para avançar nesse campo, portanto, é investigar as práticas de gestão do conhecimento em um caso específico. O Instituto Fábrica do Milênio (IFM) é uma rede de âmbito nacional, com cerca de setecentos (700) pesquisadores e de caráter multidisciplinar. Ela foi formada com o intuito de desenvolver tecnologias de manufatura que possam resultar em benefícios para as empresas nacionais. Produz uma significativa quantidade de conhecimentos na forma de capacitação de pesquisadores e produção intelectual; bem como artigos, patentes e produtos, que precisam ser disseminados para a comunidade científica e empresarial (INSTITUTO FÁBRICA DO MILÊNIO, 2006).

\section{Objetivo}

O objetivo do trabalho é identificar as práticas de gestão do conhecimento utilizadas por grupos de pesquisa que integram a rede IFM. Ele contribui para conhecer a realidade e identificar problemas e necessidades dos grupos de pesquisa em relação às práticas de gestão do conhecimento. $\mathrm{O}$ contexto especial de pertencerem a uma rede visa verificar também a existência ou não de práticas voltadas para a aquisição e compartilhamento entre grupos da rede; considerando na análise o ponto de vista do grupo de pesquisa.

\section{Definição de grupos de pesquisa}

A pesquisa científica em nossa sociedade pode se dar em diferentes tipos de organizações: instituições privadas, agências governamentais e instituições de ensino. Em qualquer um dos casos pode-se identificar uma unidade elementar, comumente denominada de grupo de pesquisa, laboratório acadêmico, laboratório de ensino, laboratório de pesquisa ou laboratório de desenvolvimento (RENAUX et al., 2001; STRAUHS et al., 2000). No artigo emprega-se a denominação grupo de pesquisa.

A missão principal de um grupo de pesquisa é gerar conhecimento através de seus processos de pesquisa. Nesses processos são produzidos ativos tangíveis e intangíveis. No caso de grupos de pesquisa em instituições de ensino, os mais valiosos são intangíveis, fato que pode ser verificado pela missão principal: formar profissionais capacitados a fazer uso imediato de tecnologias atuais e a gerar informações de alto valor agregado (STRAUHS; ABREU; RENAUX, 2000 e 2002).
Grupos organizados dentro de instituições de ensino, segundo Maculan e Furtado (2000), são formados por equipes multidisciplinares de professores e alunos, tanto de graduação como de pós-graduação, relacionados com determinadas linhas de pesquisa e escolhidos por interesses e competências pessoais (STRAUHS; ABREU; RENAUX, 2000 e 2002).

Os grupos de pesquisa em instituições de ensino surgem a partir do pesquisador que reúne um conjunto de alunos, formando sua equipe de trabalho. Aos poucos, assume responsabilidades com o financiamento de projetos, divulgação de resultados, busca de bolsas para estudantes e demais recursos para a realização da pesquisa por meio de parcerias com empresas e instituições de fomento (MACULAN; FURTADO, 2000).

Eles possuem características bem específicas. Uma das principais é a alta rotatividade dos integrantes. Também chamado de turnover, ocorre no término da graduação ou pós-graduação, quando alunos deixam o grupo, significando a perda de conhecimentos e competências (RENAUX et al., 2001).

Segundo Carvalho et al. (2001), grupos de pesquisa apresentam também descontinuidades de linhas de fomento e a falta de procedimentos formais de documentação de projetos. Ambos dificultam a entrada de novos pesquisadores e trazem prejuízos para a memória organizacional.

$\mathrm{O}$ excesso de informações e a rapidez, com que conceitos, temas, ferramentas e métodos são substituídos, exigem uma contínua renovação dos estudos e alta especialização, características marcantes dessas organizações. A renovação constante do conhecimento em tese exige alto nível de desempenho em GC (MUNDIN, 2001).

A sobrecarga de atividades sobre os coordenadores, pesquisadores mais experientes, é outra característica marcante dos grupos. A participação desse coordenador na seleção do material e transmissão dos conhecimentos básicos é essencial e decisiva no início do processo de aprendizagem (MUNDIN, 2001). Após orientação inicial, o aluno continuará sua trajetória intelectual de maneira mais independente, mas ainda assim o acompanhamento do professor será fundamental.

De acordo com Maculan e Furtado (2000), o maior desafio enfrentado pelos grupos de pesquisa diz respeito à cooperação com empresas. A incorporação e aplicação dos conhecimentos gerados no meio industrial é um dos maiores desafios. Segundo os autores, com poucas exceções, os grupos de pesquisa brasileiros se apresentam pouco vinculados aos sistemas produtivos, impedindo a transferência de conhecimentos nos dois sentidos. Uma das explicações seriam as dinâmicas distintas de produção do conhecimento. Enquanto grupos de pesquisa mantêm o caráter de pesquisa científica e avançada, as empresas 
buscariam conhecimentos para a solução de problemas técnicos de curto prazo.

Todos os desafios apresentados devem ser enfrentados e ultrapassados, já que a atuação dos grupos de pesquisa é fundamental para a inovação e a criação dos conhecimentos necessários ao desenvolvimento econômico e social (STRAUHS; ABREU; RENAUX, 2001). A gestão do conhecimento apresenta-se com um dos principais instrumentos.

\section{Gestão do conhecimento}

A gestão do conhecimento (GC) faz parte da pauta de discussão de praticamente todas as organizações. Nonaka e Takeuchi (1997) são responsáveis pela definição pioneira e pela criação de um modelo até hoje amplamente utilizado, fundamentado em dois conceitos: a conversão e a espiral do conhecimento. O primeiro identificando os diferentes tipos de conhecimento e processos de conversão responsáveis por sua criação e disseminação. O segundo, como um modo de gerar um ciclo virtuoso que garanta a criação e transformação contínua desse conhecimento.

Os autores citam quatro tipos de conversão: socialização (tácito-tácito); externalização (tácito-explícito); internalização (explícito-tácito); e combinação (explícito-explícito). No decorrer dos anos esta abordagem amadureceu tornando-se um pilar essencial de diversos modelos de gestão. Alguns exemplos são: Terra (2001), Oliveira Jr (2001) e, mais recentemente, Salabria (2007).

Paralelamente, há conceitos correlatos à GC, desenvolvidos e incorporados na rotina das organizações. São os conceitos competência (ZARIFIAN, 2001; HAMEL; PRAHALAD, 1995); aprendizagem organizacional (SENGE, 1990; GARVIN, 1998; SOUZA, 2004) e comunidades de prática (DAVENPORT; PRUSAK, 1998; SENGE; KÄUFER, 2003; NICKOLS, 2000; MOSCONI, 2003).

Amaral (2005) apresenta uma compilação de acepções do termo gestão do conhecimento, culminando em uma definição que combina estes conceitos. A gestão do conhecimento é vista como um programa, um conjunto de ações, que visa aumentar continuamente a competência dos funcionários e a eficiência dos processos de negócio organizacionais, por meio de ações que fomentem um ambiente de estímulo à aprendizagem organizacional e à criação de comunidades de prática.

Adaptando-a, define-se como: o conjunto de ações que visam apoiar a criação, o registro e o compartilhamento de conhecimentos dentro da organização, aumentando continuamente a competência individual de cada funcionário e a aprendizagem organizacional. Há diferentes tipos de ações que podem contribuir com o objetivo, as quais são denominadas neste trabalho de práticas de gestão do conhecimento.

\section{A gestão do conhecimento em grupos de pesquisa}

De acordo com Strauhs et al. (2001), a alta rotatividade dos alunos representa uma perda para o grupo de pesquisa, pois importantes conhecimentos e ativos intangíveis acompanham o aluno que deixa o grupo. Segundo os autores, perdem-se competências, formadas pela união dos conhecimentos e experiências de todos os pesquisadores (STRAUHS; ABREU; RENAUX, 2001).

Segundo esses autores, o ideal seria que a saída de um integrante do grupo de pesquisa fosse precedida de uma fase de "[...] transferência do conhecimento adquirido [...] para os outros integrantes" (STRAUHS et al., 2000, p. 25). Trata-se de uma visão simplificadora. A solução, no contexto da GC, é mais complexa do que uma mera fase de transição. Independente disso, a menção é um reconhecimento da importância da GC por pesquisadores não envolvidos com o tema; mais imparciais, portanto.

Além disso, iniciativas de gestão do conhecimento podem ser direcionadas aos grupos de pesquisa com os objetivos de: estimular a criação de conhecimentos continuamente; estimular o compartilhamento dos conhecimentos além das fronteiras do grupo de pesquisa; acompanhar a evolução do nível de conhecimento dos integrantes do grupo; permitir o acesso, a geração e a organização das informações geradas no mundo (RENAUX et al., 2001).

Brand (1998) demonstra, a partir da experiência da 3M, que a conversão tácito-tácito do modelo de Nonaka; Takeuchi (1997) é fundamental para favorecer a gestão do conhecimento em organizações cujo objetivo principal é a inovação, tal qual em grupos de pesquisa, resultado este reforçado por Al-Beraidi; Rickards (2006) e Andriopoulos (2001).

Com a participação do grupo em redes de pesquisa a gestão do conhecimento assume ainda maior importância. Os modelos de GC deveriam apoiar também o compartilhamento com outros grupos de pesquisa e, idealmente, incluir empresas ou outras organizações que porventura participem da rede. Ampliam-se os desafios da conversão e retenção do conhecimento gerado.

As problemáticas da GC aplicada a grupos de pesquisa e da GC aplicada às redes são pouco conhecidas e não foram encontrados modelos teóricos durante a revisão. Fez-se necessário criar um referencial específico para o trabalho. Optou-se por fazê-lo a partir de referências de trabalhos correlatos: tanto de GC aplicada a organizações com alto nível de inovação, quanto trabalhos sobre o funcionamento de grupos de pesquisa. São eles: Silva (2002); Silva et al. (2003); Sato (2001); Latour e Woolgar (1997); Leonard e Straus (1997); Bauer e Macedo (2000); Marcovitch e Baião (1999); Mosconi (2003); Amaral et al. (2003) e Souza (2004). A próxima seção descreve o modelo teórico utilizado. 


\section{Modelo teórico empregado na pesquisa}

As organizações têm sido analisadas e consideradas a partir da abordagem por processos de negócio (GONÇALVES, 2000). Iniciativas em gestão do conhecimento (GC), mais modernas também, têm sido realizadas a partir da visão de processos da organização.

O levantamento bibliográfico procurou, então, identificar a definição do processo de pesquisa e as atividades que a compõem. Como não foram encontradas referências específicas, fez parte da pesquisa a sua identificação. Utilizou-se como ponto de partida o trabalho de Latour e Woolgar (1997) que, a partir de um enfoque antropológico, descreve o processo de pesquisa científica.

$\mathrm{O}$ processo de pesquisa foi definido como o conjunto de atividades pelas quais um pesquisador planeja e realiza um projeto de pesquisa, considerando o seu fim como sendo a divulgação do trabalho (por exemplo: defesa da dissertação ou tese). A versão inicial de modelo teórico de processo de pesquisa foi definida guiando-se em Latour e Woolgar (1997). Foram identificadas 9 fases segundo a referência citada, são elas: definição de linha de pesquisa e tema; aquisição de recursos; seleção do aluno; adaptação do pesquisador ao grupo; elaboração do projeto de pesquisa; coleta de dados; análise dos dados; e divulgação dos resultados parciais e finais.

A revisão bibliográfica sobre pesquisa científica demonstrou também que esse processo é intimamente ligado à gestão do conhecimento. No decorrer da pesquisa científica, vários conhecimentos são absorvidos, criados e divulgados (LIYANAGE et al., 1999).

As atividades do processo de pesquisa que contribuem para os ciclos de transformação do conhecimento são denominadas, neste trabalho, de práticas de gestão do conhecimento, pois são atividades ou iniciativas que promovem a gestão do conhecimento durante o processo de pesquisa. Além dessas atividades, incluem-se os contatos realizados por meio de redes informais, comunidades de interesse e comunidades de prática, as quais também contribuem para a transformação e disseminação do conhecimento. Um processo de pesquisa e suas práticas em gestão do conhecimento resultam na formação de pessoas, publicações e patentes, já em casos mais raros, produtos.

Com o intuito de realizar esta análise, empreendeu-se um levantamento da bibliografia sobre o tema, que permitiu identificar 42 práticas de gestão do conhecimento, específicas para grupos de pesquisa. Elas foram agrupadas segundo as fases do processo de pesquisa e são descritas na Tabela 1 . Ao final de cada prática identifica-se a fonte bibliográfica.

\section{Método}

\subsection{Escolha do método}

Em relação ao seu objetivo, a pesquisa pode ser classificada como descritiva e qualitativa, pois procura descrever as características de um determinado fenômeno (CERVO; BERVIAN, 1983); há a preocupação com a atuação prática (GIL, 1999) e o objeto de pesquisa não é medido através de métodos e relações objetivas, e sim através da verificação de relações entre várias situações e aspectos subjetivos.

A estratégia, de acordo com a classificação de Yin (1994), é o estudo de caso. A coleta de dados pode ser classificada como entrevista em profundidade, segundo Roesch (1999), pois esta forma é adequada para pesquisas qualitativas realizadas em situações e contextos que não foram previamente estudados. A estratégia adotada mostrou-se capaz de lidar com a quantidade de grupos e restrições de tempo. Delineamentos mais profundos e de emersão, tais como observação direta ou mesmo pesquisa ação, apesar de interessantes, seriam inviáveis devido ao tempo disponível para a realização da pesquisa.

\subsection{Etapas da pesquisa}

O trabalho foi dividido em sete etapas, são elas:

a) revisão bibliográfica sobre $\mathrm{GC}$, grupos e redes de pesquisa;

b) criação do modelo teórico sobre práticas de GC aplicáveis a grupos de pesquisa;

c) escolha dos grupos para a composição da amostra. Desenvolvimento de critérios e escolha de uma amostra de grupos de pesquisa representativa da rede IFM;

d) desenvolvimento dos instrumentos de coleta de dados. Desenvolvimento de dois roteiros de entrevistas; um destinado aos coordenadores e professores pertencentes ao grupo de pesquisa e outro aos demais pesquisadores. Elaborou-se também um roteiro de itens a serem observados ao se visitar cada grupo: documentos e aspectos ambientais;

e) teste dos instrumentos. A pesquisadora trabalhou durante o período de uma semana junto a um dos nós da rede IFM. Os seus integrantes foram entrevistados no início da semana e as ações do grupo foram acompanhadas em detalhe no decorrer do período. Os roteiros foram aprimorados conforme os resultados do teste;

f) levantamento das práticas de GC nos grupos da amostra. Identificação das práticas por meio de entrevistas com pesquisadores e professores coordenadores. Os instrumentos (seção 7.3) foram construídos segundo o modelo expresso na Tabela 1 , resultado da segunda etapa da pesquisa; 
Tabela 1. Práticas de GC em grupos de pesquisa identificadas na literatura.

\begin{tabular}{|c|c|}
\hline Fases & Descrição \\
\hline \multirow{4}{*}{$\begin{array}{l}\text { 1. Definição } \\
\text { de linhas } \\
\text { e temas } \\
\text { de pesquisa }\end{array}$} & $\begin{array}{l}\text { 1.1 Conversa do aluno com o orientador sobre uma oportunidade de pesquisa e a sua viabilidade. (LATOUR; WO- } \\
\text { OLGAR, 1997); }\end{array}$ \\
\hline & 1.2 Relação bem definida entre projetos distintos do grupo. (Adaptado de SILVA, 2002); \\
\hline & $\begin{array}{l}\text { 1.3 Definição de temas em conjunto com atores externos ao grupo: outros grupos, outras instituições de pesquisa. } \\
\text { Quantos projetos? Com que freqüência se comunicam? Adaptado: Silva (2002); e }\end{array}$ \\
\hline & $\begin{array}{l}\text { 1.4 Definição de temas em conjunto com atores externos ao grupo: empresas e organizações. } \\
\text { Quantos projetos? Com que freqüência se comunicam? Adaptado: Silva (2002). }\end{array}$ \\
\hline \multirow{5}{*}{$\begin{array}{l}\text { 2. Aquisição } \\
\text { de recursos }\end{array}$} & 2.1 Parcerias com empresas e instituições. (LATOUR; WOOLGAR, 1997); \\
\hline & 2.2 Divulgação e informe de editais para envio de projetos de pesquisa; \\
\hline & $\begin{array}{l}2.3 \text { Negociação e combinação de recursos necessários. Em empresas, outros grupos, etc. (MARCOVITCH; BAIÃO, } \\
\text { 1999); }\end{array}$ \\
\hline & 2.4 Elaboração dos estudos de viabilidade necessários. (MARCOVITCH; BAIÃO, 1999); e \\
\hline & 2.5 Programação e alocação dos recursos necessários. (MARCOVITCH; BAIÃO, 1999). \\
\hline \multirow[t]{5}{*}{$\begin{array}{l}\text { 3. Seleção } \\
\text { do aluno }\end{array}$} & $\begin{array}{l}\text { 3.1 Verificação do perfil de entrada do aluno, que contemple conhecimentos técnicos necessários para a pesquisa. } \\
\text { (SATO, 2001); }\end{array}$ \\
\hline & $\begin{array}{l}\text { 3.2. Utilização de critérios que permitam ou incentivem o ingresso de alunos de outras instituições. (SILVA et al., } \\
\text { 2003); }\end{array}$ \\
\hline & 3.3 Coleta de indicações de alunos de outros orientadores. (SILVA et al., 2003); \\
\hline & $\begin{array}{l}\text { 3.4 Construção de base de curriculum vitae contendo informação dos alunos que participaram da seleção. (SILVA } \\
\text { et al., 2003); e }\end{array}$ \\
\hline & 3.5 Entrevista conjunta com integrantes do grupo e o aluno que está sendo selecionado. (SILVA et al., 2003). \\
\hline
\end{tabular}

4. Adaptação 4.1 Existência de procedimento formal para apresentação de sistemas computacionais e instalações do grupo. Feita do aluno ao de forma formal ou informal. (SILVA et al., 2003);

grupo $\quad 4.2$ Definição do perfil a ser formado no aluno com a realização da pesquisa. Existe um perfil específico que se deseja formar no aluno que participa do grupo? (SILVA et al., 2003);

4.3 Acompanhamento da formação do perfil do aluno. (Adaptado: SILVA, 2002);

4.4 Apresentação da importância da gestão do conhecimento para conscientizar o aluno a compartilhar seus conhecimentos. (SILVA et al., 2003);

4.5 Processo de treinamento ou programa de capacitação formal para todos os alunos. (SILVA, 2002; SATO, 2001);

4.6 Manutenção de lista com referências bibliográficas básicas relacionadas ao tema de pesquisa do aluno, feita pelo orientador. (SILVA et al., 2003); e

4.7 Identificação e discussão das referências básicas entre orientador e aluno. (SILVA et al., 2003).

5. Projeto de 5.1 Consulta a bibliotecas que contenham revistas, livros, CDs, vídeos, manuais. Realizada com sistema informatizapesquisa do de busca. (SILVA et al., 2003);

5.2 Leitura e escrita de fichamentos: escrita da análise e de comentários sobre referências bibliográficas pesquisadas. Compartilhamento dos fichamentos. (SILVA et al., 2003);

5.3 Conversas entre os integrantes do grupo (podem ser formais ou informais) com objetivo de discutir os tópicos que serão abordados na pesquisa. (LATOUR; WOOLGAR, 1997; BAUER; MACEDO, 2000; YIN, 1994); e

5.4 Reunião de orientadores com alunos sobre as teorias que serão abordadas, os objetivos e os resultados que se espera alcançar. (SILVA et al., 2003) (Adaptado: SOUZA, 2004; YIN, 1994);

6. Planejamento 6.1 Orientações sobre os mecanismos de coleta de dados e a maneira de utilizá-los (instruções de como ser imparcial da coleta e crítico em relação à elaboração dos meios de coleta). (YIN, 1994);

de dados $\quad 6.2$ Visita a empresas e outros grupos de pesquisa com o objetivo de discutir sobre como será realizada a coleta de dados. (SILVA et al., 2003);

6.3 Escrita dos passos que serão realizados na coleta de dados. (SILVA et al., 2003; YIN, 1994);

6.4 Detalhamento dos meios pelos quais será realizada a coleta de dados. (SILVA et al., 2003; YIN, 1994); e

6.5 Detalhamento de como os dados coletados serão analisados. (YIN, 1994).

7. Coleta de 7.1 Realização da coleta de dados conjuntamente com outros integrantes do grupo. (YIN, 1994);

dados $\quad 7.2$ Intercâmbio em outros grupos de pesquisa para a realização da coleta de dados. (SILVA et al., 2003); e

7.3 Organização e documentação dos dados coletados. (YIN, 1994). 
Tabela 1. Continuação...

\begin{tabular}{ll}
\hline \multicolumn{1}{c}{ Fases } & \multicolumn{1}{c}{ Descrição } \\
\hline 8. Análise dos & 8.1 Trabalhos em conjunto para estimular a comunicação entre os alunos e auxiliar na análise de dados e solução de \\
dados & problemas. (Adaptado: SILVA, 2002); SILVA, et al., 2003; BAUER; MACEDO, 2000; Yin, 1994); \\
coletados & 8.2 Uso de imagens, matrizes e sequiências cronológicas para melhor visualizar os dados coletados. Acesso comparti- \\
& lhado? (YIN, 1994); e \\
& 8.3 Documentação das conclusões parciais e finais. Compartilhado? (YIN, 1994). \\
\hline 9. Divulgação & 9.1 Uso de padrões de documentos, como padrões para atas, projetos, relatórios de pesquisa e de trabalho. \\
dos resultados & (SILVA et al., 2003); \\
parciais e & 9.2 Repositório de arquivos, como: textos, apresentações, eventos, padrões de documentos. (SILVA et al., 2003); \\
finais & 9.3 Repositório de projetos contendo informações e resultados de projetos em andamento e já finalizados. (SILVA \\
& et al., 2003); \\
& 9.4 Realização de reuniões ou palestras com o intuito de expor o andamento e os resultados parciais de pesquisas. \\
& (SILVA et al., 2003); adaptado de Souza (2004); \\
& 9.5 Publicação de artigos em revistas, livros e meios eletrônicos. (LATOUR; WOOLGAR, 1997); e \\
& 9.6 Apresentação de artigos e trabalhos em congressos e feiras setoriais. (LATOUR; WOOLGAR, 1997; SOUZA, \\
& 2004). \\
\hline
\end{tabular}

g) compilação dos resultados da pesquisa de campo. Essa etapa consistiu na análise dos resultados obtidos durante as etapas de pesquisa de campo.

\subsection{Instrumentos de coleta de dados}

Foram obtidos dois roteiros de entrevista, denominados respectivamente de roteiros 1 e 2 . Ambos formados por questões semi-abertas, em que cada respondente tem liberdade para discorrer sobre temas agrupados por seções.

No caso do roteiro 1, destinado aos professores e coordenadores, eram cinco as seções: perfil do entrevistado (contendo 4 questões sobre a formação em pesquisa, tempo e papel dentro do grupo de pesquisas); práticas de GC (contendo 2 questões abrangentes que buscavam descrever as etapas principais do processo de pesquisa utilizado pelo grupo e as atividades e práticas relacionadas com a GC em cada uma das etapas); comunicação (contendo 1 questão que visava identificar as ferramentas de comunicação mais utilizadas e os tipos de conversão do conhecimento associados a cada uma delas, conforme o uso realizado pela equipe); Ferramentas (com 1 questão aberta solicitando a identificação dos sistemas de informações e métodos relacionados com a GC, em que cada pesquisador explicava detalhadamente o significado de método e ferramenta); e comentários finais (contendo 2 perguntas abertas sobre quais os aspectos positivos e negativos identificados pelo pesquisador relacionado à GC). Ao todo, portanto, eram 11 questões.

A resposta sobre a pergunta da seção 2, "Práticas", foi auxiliada por um cartão de apoio. Ele descrevia as práticas de GC identificadas na literatura por meio da revisão bibliográfica (Tabela 1). Esta parte da entrevista foi subdividida em três etapas. Na primeira, solicitou-se aos respondentes descrições das fases do processo de pesquisa do grupo. Em seguida, explicava-se o que era a GC e questionava-se sobre as práticas utilizadas em cada fase do processo de pesquisa, de maneira espontânea, sem sugerir qualquer prática. Em seguida, era apresentado o cartão de apoio com as práticas identificadas na literatura e solicitava-se a indicação das práticas utilizadas, incluindo o grau de intensidade entre formal, informal, ad-hoc e inexistente. Obteve-se, portanto, menções espontâneas e dirigidas.

$\mathrm{O}$ roteiro 2 , destinado aos pesquisadores de todos os níveis, foi dividido em 4 seções: perfil do entrevistado (com 2 questões, uma aberta e outra fechada, sobre as características do entrevistado). A questão fechada avaliava o nível entre 7 possíveis níveis, desde iniciação científica até pós-doutorado; práticas e atividades (contendo 6 questões abertas descrevendo as etapas do processo de pesquisa realizada por ele e práticas de GC empregadas na sua pesquisa); comunicação (uma única pergunta, idêntica a do roteiro anterior, sobre os canais de comunicação, identificando o nível de utilização em uma escala de zero a cinco utilizada e não utilizada, e o contexto, isto é, se utilizado internamente no grupo, com outros grupos de pesquisa da rede ou empresas e outras instituições); ferramentas (uma única questão aberta idêntica a do roteiro anterior).

\subsection{Descrição da rede de pesquisas do Instituto Fábrica do Milênio e da amostra utilizada}

O Instituto Fábrica do Milênio (IFM) é uma organização que atua em âmbito nacional e reúne pesquisadores da área de manufatura, alocados predominantemente em instituições de ensino superior (IFM, 2006). Cada grupo 
de pesquisa é composto por um ou mais professores e um conjunto de alunos de pós-graduação e graduação que se dedicam ao estudo de um tema, todos relacionados com a área de manufatura, conforme definição de grupo apresentada. A rede IFM é organizada por chamados nós de pesquisa, conforme a definição adotada na rede, cada uma delas formada por um ou mais grupos de pesquisa. $\mathrm{Na}$ época de realização da pesquisa de campo a rede IFM era formada por 31 nós.

O número total de pesquisadores envolvidos na rede era de aproximadamente 350 na ocasião da pesquisa, resultando em aproximadamente 11 pesquisadores por nó. A média de professores ou pesquisadores orientadores envolvidos era próxima a 2 por grupo. A maioria dos nós operava dentro de instituições de ensino superior. Apenas 3 dos 31 nós da rede eram do tipo institutos de pesquisa.

Os nós de pesquisa que formam a rede do IFM eram classificados em quatro áreas: gestão da cadeia de suprimentos; gestão do desenvolvimento de produtos; fabricação e automação; e gestão da transformação organizacional e qualidade.

O levantamento de práticas foi realizado empregando-se uma amostra, devido às restrições de tempo citadas. O procedimento adotado é a amostragem estratificada proporcional, selecionando-se uma lista para representar a população cujo número de nós escolhidos em cada área de pesquisa é proporcional ao número da população (AAKER et al., 2001). Os critérios de estratificação foram áreas de pesquisa e tamanho dos grupos.

A área de pesquisa se justifica pelas diferentes abordagens conceituais e metodológicas, distintas conforme o assunto estudado. No caso da rede do IFM, há uma distinção clara entre grupos que utilizam métodos experimentais, como os da área de fabricação e automação, e outros com métodos afins às ciências humanas, mais especificamente gestão. Julgou-se que estas diferenças poderiam levar a práticas distintas em termos de gestão do conhecimento.

O critério tamanho poderia também influir na medida da estruturação do grupo. Grupos maiores poderiam apresentar práticas mais burocratizadas que grupos menores. A estratificação procurou controlar essa influência. Neste caso o critério foi o número de professores orientadores do grupo. Grupos menores são aqueles com apenas um professor orientador (isto é, professor responsável pela orientação de alunos de pós-graduação). Grupos maiores são aqueles com mais de um. No caso da rede IFM não passam de 3 e a maioria dos grupos grandes é formada por 2 professores pesquisadores.

Foram escolhidos 7 nós de pesquisa da rede IFM, sendo 2 na área de fabricação e automação; 1 na área de gestão da cadeia de suprimentos; 1 na área de gestão da transformação e qualidade; e 3 na gestão do desenvolvimento de produtos. Dos 7 nós de pesquisa escolhidos para compor a amostra, 2 se enquadram no caso de grupos de pesquisa menores. Para verificar a conformidade da amostra com o espaço total de nós elaborou-se dois gráficos que apresentam a escolha em relação ao critério área de pesquisa, apresentados na Figura 1. No primeiro gráfico da Figura 1 são apresentados todos os nós do IFM distribuídos entre as quatro áreas de pesquisa.

É interessante ressaltar que alguns nós atuam em mais de uma área de pesquisa, e por isso a soma de todos os nós da população excede o número total de nós da rede. No gráfico da direita são apresentados os nós que formam o espaço amostral, também distribuídos pelas quatro áreas de pesquisa. Todos os nós selecionados para compor a amostra são dedicados somente a uma das quatro áreas. Observando os dois gráficos, verifica-se que as proporções dos nós em cada uma das áreas são correspondentes entre a amostra e a população.

Entrevistou-se inicialmente o professor coordenador, isto é, o responsável pelo grupo segundo os cadastros obtidos com os administradores da rede de pesquisa. Nos casos

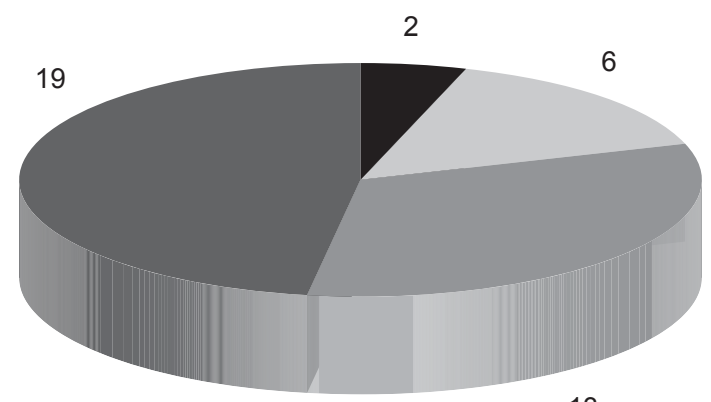

13

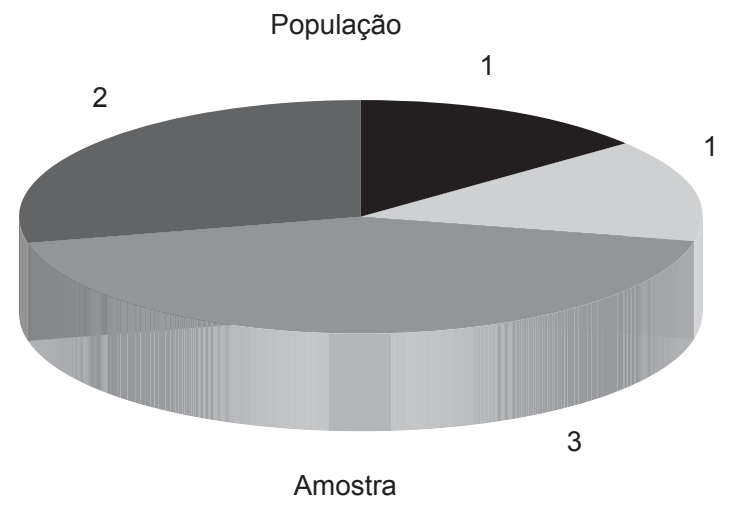

Gestão da transformação organizacional e qualidade

$\square$ Gestão das cadeias de suprimentos

$\square$ Gestão do desenvolvimento de produto

$\square$ Fabricação e automação

Figura 1. Distribuição dos grupos do IFM em áreas de pesquisa. 
de grupos maiores, entrevistou-se um segundo professor orientador, permitindo captar eventuais diferenças.

Assumindo que os melhores alunos são os que possuem o nível mais elevado nas práticas de gestão do conhecimento do grupo, a escolha dos entrevistados do tipo pesquisador (alunos e pesquisadores orientados pelos professores) foi baseada na indicação feita pelo coordenador do grupo de pesquisa: solicitado a indicar os melhores alunos. Foi selecionado um representante de cada nível de escolaridade: aluno de iniciação científica, mestrando, doutorando e pós-doutorando (quando disponível). Com isso, foram entrevistados em média cinco integrantes de cada grupo de pesquisa da amostra, número que decresceu no caso dos grupos de pesquisa que não apresentam integrantes em todas as categorias citadas.

\subsection{Realização das entrevistas}

Os testes foram realizados no período de duas semanas, durante o qual a pesquisadora acompanhou um determinado grupo de pesquisas. $\mathrm{O}$ acompanhamento visou verificar com profundidade se as percepções fruto das entrevistas (feitas no primeiro dia) se verificavam em uma análise detalhada, in loco.

Para cobrir os sete nós de pesquisa foram realizadas trinta e três entrevistas, treze com professores e vinte com alunos, totalizando trinta e cinco horas e meia de entrevistas. A duração média de quarenta minutos com os alunos e uma hora e quarenta minutos com os professores (Tabela 2) estão de acordo com as estimativas de tempo que foram previstas no momento da elaboração dos roteiros: trinta a sessenta minutos para os alunos e duas horas para os professores. Na Tabela 3 a seguir podem ser observados os números de alunos e de professores entrevistados em cada um dos grupos e nós de pesquisa.

\subsection{Método de análise dos dados}

Os dados coletados em cada entrevista foram documentados separadamente em um relatório específico. Em seguida, um novo relatório foi elaborado para cada grupo de pesquisa (nó). Apenas as práticas citadas por coordenadores e pesquisadores de maneira conjunta foram consideradas como práticas efetivas no grupo. Os resultados são descritos na próxima seção.

\section{Resultados do levantamento das práticas de gestão de conhecimento}

Os resultados são apresentados em três partes: sobre o processo de desenvolvimento de pesquisa; as práticas de GC identificadas e que não haviam sido encontradas na literatura; e a análise da freqüência observada de uso das práticas.

\subsection{O processo de pesquisa}

Todos os grupos pesquisados concordaram com a organização do processo de pesquisa nas nove fases apresentadas. Porém, duas novas fases foram citadas como relevantes, são elas:

a) planejamento da coleta de dados. Fase em que os experimentos ou coletas de dados em campo são projetados. Segundo os grupos, deveria ser anterior ou parte da fase "Projeto de Pesquisa"; e

b) comunicação e obtenção de conhecimentos de ex-alunos do grupo. Trata-se da manutenção dos contatos com ex-alunos. Apesar de não mencionada na literatura, foi citada espontaneamente por parte significativa dos grupos. Os grupos que não a mencionaram foram consultados posteriormente e todos, com exceção de um apenas, concordaram

Tabela 2. Duração das entrevistas realizadas no IFM. (LIMA; AMARAL, 2008).

\begin{tabular}{lc}
\hline \multicolumn{2}{c}{ Estatísticas das entrevistas } \\
\hline Número de alunos & 20 \\
Duração total - alunos & $14: 35: 00$ \\
Duração média da entrevista - aluno & $00: 43: 45$ \\
Número de professores & 13 \\
Duração total - professores & $21: 40: 00$ \\
Duração média da entrevista - professor & $01: 40: 00$ \\
Total de entrevistados & 33 \\
Duração total & $36: 15: 00$ \\
\hline
\end{tabular}

Tabela 3. Número de integrantes de cada nó de pesquisa.

\begin{tabular}{|c|c|c|c|c|c|c|c|c|c|c|}
\hline \multirow[t]{2}{*}{ Nó } & \multirow[t]{2}{*}{ Grupo } & \multicolumn{7}{|c|}{ Alunos } & \multirow{2}{*}{\multicolumn{2}{|c|}{ Professor }} \\
\hline & & Tc. & IC. & Ms. & Dr. & P-Dr. & & & & \\
\hline 1 & 1 & 2 & 13 & 10 & 17 & 0 & & 42 & & 3 \\
\hline 2 & 2 & 2 & 16 & 7 & 4 & 1 & & 30 & & 3 \\
\hline 3 & 3 & 0 & 2 & 1 & 3 & 0 & & 6 & & 3 \\
\hline 4 & 4 & 1 & 12 & 9 & 6 & 2 & & 31 & & 2 \\
\hline \multirow[t]{2}{*}{$5 *$} & $5 \mathrm{~A}$ & 0 & 1 & 13 & 5 & 0 & 19 & & 1 & \\
\hline & $5 \mathrm{~B}$ & 0 & 2 & 3 & 3 & 0 & 8 & 27 & 1 & 2 \\
\hline 6 & 6 & 0 & 10 & 25 & 13 & 0 & & 48 & & 5 \\
\hline \multirow[t]{2}{*}{$7 *$} & $7 \mathrm{~A}$ & 0 & 10 & 4 & 0 & 0 & 14 & & 1 & \\
\hline & $7 \mathrm{~B}$ & 0 & 2 & 9 & 0 & 0 & 11 & 25 & 1 & 2 \\
\hline
\end{tabular}

Tc.:Técnico; IC.: Iniciação Científica; Ms.: Mestrado; Dr.:Doutorado; e P-Dr.: Pós-doutorado; *Dois grupos (A e B) foram entrevistados nos nós 5 e 7. Prof.: Professores. (LIMA; AMARAL, 2008). 
com a sua importância. Não foi detectada nenhuma prática de Gestão do Conhecimento em vigor, mas os entrevistados fizeram sugestões de possíveis ações. Elas são descritas na Tabela 4.

\subsection{Práticas de GC identificadas na rede Instituto Fábrica do Milênio e não presentes no modelo}

Além das novas práticas relacionadas com a área de comunicação com ex-alunos do Grupo, algumas práticas de gestão do conhecimento indicadas pelos alunos e professores entrevistados não haviam sido encontradas anteriormente na literatura sobre gestão do conhecimento. Elas são apresentadas na Tabela 5. Uma vez somadas às práticas identificadas na literatura (Tabela 1), obtém-se o conjunto de práticas de GC para grupos de pesquisa.

\subsection{Síntese das melhores práticas identificadas}

Os itens a seguir descrevem as práticas de GC por temas e na ordem de maior ocorrência. Parte delas citada espontaneamente pelos entrevistados e demais registradas após apresentação do cartão de práticas compiladas da literatura (Tabela 1).

a) seminários, reuniões e palestras sobre os projetos de pesquisa em andamento (Prática 9.4). A prática de maior incidência é a realização de eventos internos, tais como: apresentações feitas pelo aluno ao grupo, com objetivo de mostrar e discutir trabalhos em andamento; apresentações periódicas do andamento dos projetos; e, com única incidência, organização de reuniões de trabalho com outros grupos de pesquisa ou empresas parceiras do projeto. Apenas um dos grupos não apresentou indícios desta prática relacionada com a conversão do tipo socialização (tácito-tácito);

b) participação do professor na pesquisa. Trata-se do conjunto de práticas relacionadas com a socialização promovida pelo professor (conversão tácito-tácito), são as práticas: 1.1, 5.4 e 5.5. Em todos os grupos ao menos uma dessas práticas foi citada como fundamental (por alunos e professores). A explicação é que muitas informações, tais como projetos passados e resultados obtidos, são lembradas apenas pelos orientadores;

c) ambiente de colaboração e integração entre os pesquisadores do mesmo grupo. Compreende duas práticas. Confraternizações, culturais e esportivas, fora do horário de trabalho (4.11). Permanência dos alunos no laboratório e planejamento do espaço físico de forma a estimular à convivência (4.12). Indicam que um ambiente de compartilhamento é fundamental para a gestão do conhecimento segundo a maioria dos grupos pesquisados. Este ambiente favorece a socialização (conversão tácito-tácito);

d) facilitador. Parcela significativa dos grupos que citaram as duas práticas anteriores, julgou fundamental o papel de certos alunos que agem no grupo como facilitadores. Eles atuariam espontaneamente como promotores principais dessas atividades, não tendo a GC como principal meta. Portanto, identificar este tipo de perfil e incentivar a ação destes

Tabela 4. Práticas relacionadas à comunicação com ex-alunos. (LIMA; AMARAL, 2008).

\begin{tabular}{lcc}
\hline \multicolumn{1}{c}{ Práticas } & Ocorrência nos grupos de pesquisa \\
\cline { 2 - 3 } & $\begin{array}{c}\text { Número de } \\
\text { grupos }\end{array}$ & \% \\
\hline $\begin{array}{l}\text { 1. Realimentação da universidade em relação aos profissionais que a mesma formou, por meio } \\
\text { da comunicação com ex-alunos; }\end{array}$ & 32,8 \\
$\begin{array}{l}\text { 2. Manter contato com ex-alunos, pois pode facilitar a associação de parcerias e colaborações, } \\
\text { de menor ou maior grau, com o grupo de pesquisa ou organizção onde trabalham; }\end{array}$ & 3 \\
$\begin{array}{l}\text { 3. Comparação entre as atividades realizadas no grupo e as atividades realizadas nas organiza- } \\
\text { ções onde os ex-alunos trabalham; }\end{array}$ & 28,8 \\
$\begin{array}{l}\text { 4. Acompanhamento contínuo na vida do indivíduo e rastreabilidade do aluno, como feito em } \\
\text { produtos. Muitas vezes os ex-alunos ocupam cargos avançados nas organizações; }\end{array}$ & 2 \\
$\begin{array}{l}\text { 5. Avaliação para verificar se o grupo está indo bem e conseguindo formar bem os alunos; } \\
\text { 6. Os clientes da universidade são os seus ex-alunos, que representam a voz que pode contri- } \\
\text { buir e dar retorno para avaliar as atividades realizadas na universidade; }\end{array}$ & 1 \\
$\begin{array}{l}\text { 7. Comunicação para montar uma rede de ex-alunos; } \\
\text { 8. Manter cadastros dos ex-alunos do grupo de pesquisa e enviar e-mail, semestralmente, }\end{array}$ & 1 \\
$\begin{array}{l}\text { solicitando a atualização; } \\
\text { 9. Seria interessante realizar seminários de ex-alunos que trabalham em organizações, com o } \\
\text { objetivo de contar suas experiências, como uma mesa redonda para realizar discussões; e para } \\
\text { reunir os ex-alunos; e }\end{array}$ & 1 \\
$\begin{array}{l}\text { 10. Reunião com ex-alunos após dois anos do término do projeto, com objetivo de apresentar } \\
\text { aos integrantes do grupo a sua situação atual, com uma análise dos benefícios que o projeto } \\
\text { trouxe para a sua formação e o que mudaria em sua pesquisa. }\end{array}$ & 1 \\
\hline
\end{tabular}


Tabela 5. Novas práticas de GC levantadas nas entrevistas. (LIMA; AMARAL, 2008).

\begin{tabular}{|c|c|}
\hline \multirow[t]{2}{*}{ Fases } & Práticas de gestão do conhecimento \\
\hline & Descrição \\
\hline \multirow{2}{*}{$\begin{array}{l}\text { 1. Definição } \\
\text { de linhas } \\
\text { e temas } \\
\text { de pesquisa }\end{array}$} & $\begin{array}{l}\text { 1.5 Definição de temas de interesse para o grupo e organização de exposições pelo professor e sobre a evolução } \\
\text { dos trabalhos conjuntos do grupo; e }\end{array}$ \\
\hline & $\begin{array}{l}\text { 1.6 Formalização do comprometimento da empresa em aplicar dados obtidos em um projeto de pesquisa desenvol- } \\
\text { vido pelo grupo. No caso de pesquisa aplicada, voltada a uma empresa. }\end{array}$ \\
\hline \multirow{2}{*}{$\begin{array}{l}\text { 2. Aquisição } \\
\text { de recursos }\end{array}$} & 2.6 Acordos formais entre empresas que fornecem oportunidades de estágio/pesquisa aos alunos; e \\
\hline & $\begin{array}{l}2.7 \text { Acordos informais, utilização de recursos em empresas ou outros grupos por troca de informações e de publi- } \\
\text { cações em conjunto. }\end{array}$ \\
\hline \multirow{5}{*}{$\begin{array}{l}\text { 3. Seleção do } \\
\text { aluno }\end{array}$} & 3.6 Co-orientação feita por professores de grupos de pesquisa diferentes; \\
\hline & $\begin{array}{l}\text { 3.7 Formalização da indicação de alunos por meio de duas cartas de indicação e referência escritas por professores } \\
\text { e destinadas ao departamento; }\end{array}$ \\
\hline & 3.8 Conversas entre professores do grupo sobre a seleção de alunos; \\
\hline & $\begin{array}{l}\text { 3.9 Apresentação informal do grupo, linhas e projetos de pesquisa nas disciplinas que o professor ministra, como } \\
\text { uma propaganda para atrair novos alunos ao grupo; e }\end{array}$ \\
\hline & 3.10 Avaliação de alunos que conhecem as disciplinas que o professor ministra e convite para ingressar no grupo. \\
\hline \multirow[t]{4}{*}{$\begin{array}{l}\text { 4. Adaptação } \\
\text { do aluno ao grupo }\end{array}$} & $\begin{array}{l}\text { 4.8 Processo de nivelamento: planilha com os principais temas que o aluno precisa conhecer para nivelar seus } \\
\text { conhecimentos e realizar sua pesquisa. Pode ser usada como uma check-list; }\end{array}$ \\
\hline & $\begin{array}{l}4.9 \text { Indicação de especialistas para auxiliar na adaptação do aluno ao grupo. Por meio da criação de interdependên- } \\
\text { cia entre as pessoas do grupo para incentivar a colaboração e o trabalho em grupo por meio de especialistas, que } \\
\text { são alunos responsáveis por determinados conhecimentos; }\end{array}$ \\
\hline & $\begin{array}{l}\text { 4.10 Confraternizações entre alunos e professores. Exemplos: a) no primeiro dia de aula da pós-graduação alunos } \\
\text { passam o dia todo com professores do grupo e realizam apresentações; b) defesas e qualificações; e c) datas im- } \\
\text { portantes (final de ano, férias e outras); e }\end{array}$ \\
\hline & $\begin{array}{l}\text { 4.11 Indicação de apostila que é passada para o aluno ao ingressar no grupo. Apostila criada por professor orien- } \\
\text { tador ensinando a escrever relatórios, artigos, teses e que apresenta lista de referências de livros e revistas que o } \\
\text { aluno deve ler e acompanhar. }\end{array}$ \\
\hline \multirow[t]{8}{*}{$\begin{array}{l}\text { 5. Projeto de } \\
\text { pesquisa }\end{array}$} & $\begin{array}{l}\text { 5.5 Planejamento formal de reuniões entre orientador e aluno, realizado no início do projeto de pesquisa. As } \\
\text { reuniões são realizadas com objetivos de avaliar o andamento, resultados da pesquisa e a qualidade do trabalho } \\
\text { desenvolvido. Para alunos de mestrado são três reuniões antes da qualificação e três antes da defesa, para alunos } \\
\text { de doutorado são cinco e quatro, respectivamente; }\end{array}$ \\
\hline & 5.6 Disciplina de metodologia de pesquisa indicada a todos os alunos de pós-graduação; \\
\hline & $\begin{array}{l}5.7 \text { Minicurso que o aluno deve fazer na biblioteca da universidade para aprender a pesquisar temas do conheci- } \\
\text { mento e normas de escrita da tese ou dissertação; }\end{array}$ \\
\hline & 5.8 Escrita contínua da tese ou dissertação durante todo o processo de pesquisa; \\
\hline & $\begin{array}{l}\text { 5.9 Sistema de controle de artigos, em planilha, contendo dados que classificam os periódicos e avaliam os artigos } \\
\text { já lidos; }\end{array}$ \\
\hline & $\begin{array}{l}\text { 5.10 Utilização de imagens na tese ou dissertação com o objetivo de apresentar: } \\
\text { - a contextualização da pesquisa; e } \\
\text { - o detalhamento do objeto de estudo. }\end{array}$ \\
\hline & $\begin{array}{l}\text { 5.11 Entrega de CD gravado pelo orientador, contendo todos os artigos e documentos que possam auxiliar o aluno } \\
\text { no projeto de pesquisa. O CD é entregue no início de cada ano a todos os alunos do grupo; e }\end{array}$ \\
\hline & 5.12 Utilização do mesmo espaço físico (laboratório). \\
\hline $\begin{array}{l}\text { 6. Planejamento } \\
\text { da coleta de dados }\end{array}$ & 6.6 Teste do questionário e do roteiro de entrevista em empresas ou em outros grupos de pesquisa. \\
\hline $\begin{array}{l}\text { 7. Coleta de } \\
\text { dados }\end{array}$ & $\begin{array}{l}\text { 7.4 Documentação de todas as referências, dados coletados e obtidos durante a pesquisa e gravados em um CD } \\
\text { anexado à tese ou dissertação, incluindo um software de busca para facilitar o acesso aos conteúdos do CD. }\end{array}$ \\
\hline $\begin{array}{l}\text { 8. Análise dos } \\
\text { dados coletados }\end{array}$ & $\begin{array}{l}\text { 8.4 Registro de comparações dos dados coletados com referências teóricas e com casos analisados, seguidos de } \\
\text { reflexões das diferenças. }\end{array}$ \\
\hline \multirow{4}{*}{$\begin{array}{l}\text { 9. Divulgação } \\
\text { dos resultados } \\
\text { parciais e } \\
\text { finais }\end{array}$} & 9.7 Realização de minicursos ministrados por alunos e professores do grupo de pesquisa; \\
\hline & $\begin{array}{l}\text { 9.8 Divulgação anual por CD institucional do grupo contendo informações do grupo e projetos, artigos e resulta- } \\
\text { dos obtidos durante o ano; }\end{array}$ \\
\hline & $\begin{array}{l}\text { 9.9 Cadastro de revistas, nas quais são definidos dados que podem ajudar na escrita e elaboração de artigos, como: } \\
\text { público-alvo, foco da revista, áreas, período para envio, normas de escrita; }\end{array}$ \\
\hline & $\begin{array}{l}\text { 9.10 Criação de página pessoal do aluno na Internet, com informações do aluno, suas publicações para download e } \\
\text { o conteúdo resultante de suas pesquisas. }\end{array}$ \\
\hline
\end{tabular}


integrantes pode ser uma recomendação para a implantação da GC em grupos de pesquisa. O que significaria uma nova prática (não citada abertamente nas entrevistas, mas sugerida por esses resultados). A conversão é do tipo socialização (tácito-tácito);

e) cadastro de documentos para divulgação (prática 9.9). Praticamente todos os grupos identificaram a existência de cadastros com informações sobre documentos, isto é, conversão do tipo externalização (tácito-explícito). $\mathrm{Na}$ grande maioria observou-se uma rede ou repositório utilizado para armazenar os principais trabalhos e listas de revistas (prática 9.9). Todos foram unânimes em considerar esta prática como vital. Porém, poucos grupos apresentaram práticas mais avançadas na área. Por exemplo, não foi verificada a preocupação com a padronização da documentação, pois apenas um grupo apresentou a prática 9.1. Também, foi encontrada apenas uma ocorrência da prática 9.8 e constatou-se que apenas 3 grupos (cerca de 40\%) apresentaram um repositório único de documentos (artigos, teses e apresentações), prática 9.3. Nestes casos, o site do grupo de pesquisa era o tipo mais utilizado; e

f) publicação e participação em eventos (Prática 9.6). Trata-se de uma prática que foi verificada em todos os grupos de pesquisa, embora tenha sido citada espontaneamente por apenas 1 deles, quanto ao seu potencial para a GC. Segundo entrevistados, o estímulo à participação frequiente em congressos torna os alunos mais motivados a discutirem o tema, a registrarem e a trocarem informações. Segundo a visão de um dos grupos que a citou espontaneamente, a cobrança por publicações e participação em congressos cria um clima positivo no registro e compartilhamento do conhecimento. O foco principal é a conversão do tácito-tácito. Há também a conversão do tipo externalização (explícito-tácito). O fato de não ter sido lembrada espontaneamente explica-se por ser algo rotineiro e quase que obrigatório da atividade de pesquisa: não sendo compreendido em um primeiro momento como uma ação de GC.

As demais práticas foram identificadas em quantidades pequenas, menor que dois grupos. Entre elas, destaca-se:

a) treinamento e mini-cursos (prática 9.7). O treinamento foi identificado como importante meio de compartilhar conhecimento em dois grupos de pesquisa. Conversão do tipo socialização (tácitotácito);

b) formação de pequenas equipes com trabalhos integrados (1.3). Segundo dois dos grupos pesquisados, a organização dos pesquisadores em pequenos grupos, conforme uma temática comum ou projeto de pesquisa integrado contribui para o compartilha- mento de informações e conhecimento; conversão do tipo socialização (tácito-tácito). Isso foi citado como células, grupos ou subgrupos. A proximidade dos temas ampliaria o interesse na geração e na retenção do conhecimento; e

c) práticas de gestão de conhecimento entre grupos. As práticas 1.3, 1.4, 1.6, 2.1, 2.3, 2.6, 2.7, 8.1, relacionadas com a conversão do conhecimento entre membros de diferentes grupos da rede de pesquisa, foram identificadas também com ocorrência pequena. Chama a atenção também o fato de serem principalmente voltadas à conversão tácito-tácito e em número pequeno frente a todas as práticas identificadas.

\subsection{Síntese das dificuldades enfrentadas pelos grupos de pesquisa na gestão do conhecimento}

Os problemas listados a seguir foram apontados pelos professores coordenadores de grupo quando questionados, de maneira aberta, no Roteiro 1. De maneira similar à seção anterior, cita-se na ordem de freqüência. O número entre parênteses indica o número de grupos em que o problema foi observado.

a) falta de tempo (5). O primeiro item em importância, citado por todos os entrevistados, foi rotulado de 'falta de tempo' e engloba respostas do tipo: "falta de tempo para disponibilizar documentos e conhecimentos"; "falta de tempo para os alunos dedicarem-se à gestão do conhecimento"; "falta de uma pessoa responsável para ajudar nas atividades de GC como cadastramento de informações do grupo"; "o grupo possui um site dinâmico, mas não há tempo de cadastrar as informações"; "o registro e o compartilhamento do conhecimento não é uma prioridade dos pesquisadores e dependeria de tempo adicional". Portanto, na visão dos entrevistados, a GC é algo que envolve tempo adicional às atividades de pesquisa e que exigiria também recursos humanos especialmente dedicados;

b) inexistência de um sistema para compartilhamento e divulgação do conhecimento (5). Falta de uma estrutura para a divulgação dos resultados interna e externamente ao grupo. Nesta categoria foram citados os seguintes problemas: "falta de um sistema que permitisse a publicação dos resultados da pesquisa de uma forma mais rápida"; "falta de um sistema de informação para reunir resultados de ensaios, testes e pesquisas de campo realizados por diferentes pesquisadores" (como, por exemplo, nem todos os dados coletados em uma pesquisa de campo são empregados em um projeto, e os dados restantes, por não serem publicados acabam se perdendo); falta de um sistema para compartilha- 
mento e gestão de documentos como artigos e teses dentro do grupo;

c) transmitir aos alunos a importância da gestão do conhecimento (3). Parte das respostas relaciona-se com a dificuldade de sensibilizar os pesquisadores quanto à importância do compartilhamento do conhecimento. São respostas tais como: "dificuldade em passar a importância da GC, e fazer com que tenha alta prioridade entre as atividades dos professores e alunos"; "os alunos apresentam uma resistência a atualizar a revisão bibliográfica"; “... compartilhar conhecimentos depende do aluno e alguns alunos não têm o costume de pensar e considerar (este aspecto)..."; “(pesquisadores)... não têm o costume de registrar seus conhecimentos de forma a possibilitar o entendimento e a utilização... (por outros pesquisadores)"; ou ainda, "Não registram seu conhecimento de uma maneira que outros possam entender";

d) dificuldade de trabalho conjunto entre grupos de pesquisa (2). Se há várias barreiras dentro de um grupo de pesquisa, foi identificado em parte dos grupos que este problema se acentua quando o projeto envolve mais de um grupo. Segundo estes entrevistados, o fato do projeto conter mais de um grupo de pesquisa dificulta ainda mais a Gestão do Conhecimento. São respostas do tipo: "hoje existe a comunicação bilateral (aluno-orientador) e seria interessante que fosse multilateral, portanto, a troca entre grupos é ainda mais difícil"; "falta de trabalho em grupo dentro do grupo". Não foram identificadas práticas formais de GC entre grupos de pesquisa. Os projetos em conjunto realizados partem em sua maioria de uma divisão de tarefas claras, conforme as especialidades previamente constituídas. A coordenação e troca de conhecimentos é realizada principalmente pelos professores coordenadores, empregando mensagens eletrônicas (e-mail);

e) excesso de informação (2). Segundo parte dos entrevistados, o excesso de informação produzida (muita informação para ser lida e assimilada) dificulta o pesquisador iniciante na escolha do que é ou não relevante. Isso dificultaria a GC, pois aumenta a quantidade de informações dentro do grupo;

f) inexistência de registros históricos sobre os trabalhos do grupo (1). Trata-se da inexistência de registros sobre informações históricas como membros, projetos de pesquisa finalizados e projetos iniciados, o contexto e decisões que levaram a estas escolhas. Isso levaria a redundâncias e um menor aproveitamento dos resultados passados do grupo. É um problema distinto do item b, pois está mais relacionado ao contexto dos trabalhos e foi citado por um grupo;

g) dificuldades de comunicação (1). Um dos grupos citou a dificuldade de comunicação com certos alunos como sendo um dos obstáculos à GC. Segundo o entrevistado, a existência de desníveis de linguagem, seja pela formação em carreiras profissionais distintas ou pouco amadurecimento do aluno, influenciaria negativamente na troca de conhecimentos; $\mathrm{e}$

h) rotatividade (1). A alta rotatividade dos alunos foi citada por apenas um grupo. Este "problema" é, na verdade, uma característica inerente aos grupos de pesquisa, especialmente aos ligados a uma instituição de ensino. Portanto, o problema de não citação por outros grupos certamente está relacionado à sua percepção como restrição. A questão principal deve ser como introduzir práticas de GC que possam ser mantidas mesmo com a rotatividade alta.

\section{Conclusões}

A pesquisa aponta que a GC está sendo vista na rede IFM como um aspecto de grande relevância, tanto por coordenadores como integrantes dos grupos de pesquisa. Todas as pessoas entrevistadas, com exceção de um coordenador de grupo, a citaram como fundamental para a qualidade dos resultados.

A centralização da difusão e retenção dos conhecimentos na figura do coordenador do grupo (professor-orientador) é um aspecto que merece destaque nos resultados encontrados. Em todos os grupos pesquisados a figura do professor-orientador ainda é o principal elemento na difusão do conhecimento. Mesmo naqueles grupos em que foram observadas práticas mais avançadas de GC, como a existência de sistemas de informação, que em tese facilitariam a transmissão do conhecimento com mediação menos intensa do coordenador.

A predominância da conversão do tipo socialização (tácito-tácito), dentre às práticas de gestão do conhecimento observadas, explica esse fenômeno. Observa-se que dos 6 conjuntos de práticas mais difundidos, apresentados no início da seção 8.3, 5 fundamentam-se nesse tipo de conversão. Isso explica a valorização do relacionamento e integração dos alunos do grupo, e a importância das atividades informais que, na falta de outros mecanismos, contribuem de maneira fundamental e significativa para a GC no grupo de pesquisa; tal como observado por Brand (1998).

Observou-se também, que parte significativa das práticas acontece de maneira parcial dentro do grupo, isto é, foi relatada por parte dos pesquisadores e professores coordenadores. Tais casos não foram considerados nos cálculos de frequiência, mas indicam uma singulari- 
dade no modo dos coordenadores conduzirem o processo de pesquisa, segmentando o grupo e gerando práticas heterogêneas. Refletem a falta de padrões e métodos sistemáticos, notada explicitamente na ausência da prática 9.1, o que dificultaria o compartilhamento de conhecimentos mesmo dentro de um único grupo de pesquisa.

Pesquisar soluções (métodos, ferramentas, entre outros) capazes de gerar procedimentos formais neste ambiente específico é, portanto, um desafio que merece atenção. $\mathrm{O}$ trabalho aponta dificuldades e oportunidades neste sentido.

Quanto às oportunidades, o uso de sistemas de informação parece ter um destaque especial na visão dos pesquisadores e professores coordenadores. Apresenta-se como uma boa prática e ao mesmo tempo como uma dificuldade. Isso significa que apesar da existência de iniciativas e sistemas de apoio em todos os grupos, os pesquisadores e coordenadores reconhecem limitações e esperam por aprimoramentos. Os benefícios considerados pelos entrevistados são: a centralização de conhecimentos em um local facilmente acessível; a distribuição e o compartilhamento de temas, referências bibliográficas e publicações do grupo; a continuidade de projetos já finalizados por meio da divulgação de teses, dissertações e artigos do grupo; a colaboração à distância por meios como fóruns, mensageiros instantâneos e enquete, e não apenas por e-mail, o principal instrumento de comunicação.

Dentre as dificuldades, a questão do tempo emerge como central no caso dos grupos pertencentes à rede IFM. É a primeira barreira para a GC, citada por praticamente todos os grupos analisados. Significa que os grupos consideram o compartilhamento e a gestão do conhecimento como atividade adicional e não o fim no processo de pesquisa. O desafio, portanto, é encontrar soluções gerenciais, sejam elas sistemas de informação ou métodos, capazes de incorporar a GC como parte integrante desse processo.

Um fato interessante é que não foram constatadas diferenças relacionadas com o perfil do grupo em termos de tipo de pesquisa, isto é, experimental (testes em laboratório) ou social (gestão). Outro fato importante é a inexistência de práticas específicas de GC direcionadas para a construção de conhecimentos em conjunto com outros nós da rede (grupos de pesquisa ou empresas). O mecanismo principal nestes casos são comunicações informais entre os pesquisadores coordenadores dos grupos, tendo o correio eletrônico (e-mail) como principal ferramenta de apoio.

O passo inicial para a melhoria da gestão do conhecimento em qualquer campo é conhecer sua realidade e os problemas específicos. Este trabalho é uma primeira contribuição no caso específico de grupos de pesquisa. Além de confirmar a importância, descreve-se um modelo inicial de processo de pesquisa e um conjunto de práticas e desafios a serem superados. Apontam-se várias possibilidades de pesquisas futuras sobre o tema: proposição de sistemas de informação para registro de conhecimentos em grupos de pesquisa; modelos de processo de pesquisa; métodos de padronização da captura de conhecimentos gerados em grupos de pesquisa; desenvolvimento de métodos e ferramentas de GC que apóiem a geração de conhecimento entre membros de diferentes grupos (em projetos conjuntos); entre outros. Explorar este campo é fundamental para aprimorar o desenvolvimento tecnológico. 


\title{
Knowledge management practices in research groups of the factory of the millennium (IFM) network
}

\begin{abstract}
Recent years have seen a growth in network research programs, with different distinct research groups bringing together competencies in their search for significant technological advances. Knowledge Management (KM) is an essential factor in these initiatives, but there are few studies about this theme. This paper describes KM practices in research groups of a Brazilian national research network called the Factory of the Millennium Institute (IFM). The research method adopted here was a multicase study, using interviews, applied to a sample of research groups of this network. The result was a conceptual research process development model, a theoretical model of best KM practices and barriers observed. The data confirms the importance of knowledge management practices and a focus on the aspect of socialization of knowledge conversion (tacit-tacit). A description is given of some directions for future research in this area.
\end{abstract}

Keywords: Information management systems. Knowledge management. Corporate portals. Research groups. Research networks.

\section{Referências bibliográficas}

AAKER, D. A.; KUMAR, V.; DAY, G. S. Pesquisa de Marketing. Tradução de Reynaldo Cavalheiro Marcondes. São Paulo: Atlas, 2001.

AL-BERAIDI, A.; RICKARDS, T. Rethinking creativity in the accounting profession: to be professional and creative. Journal of accounting \& organizational change, Melbourne - Australia, v.2, n.1, p.25-41, 2006.

AMARAL, D. C.; ROZENFELD, H.; MOSCONI, E. P. Cultivando confiança: o dia-a-dia da comunidade de prática sobre desenvolvimento de produtos. In: TERRA, J. C. C. et al. Gestão do conhecimento e e-learning na prática. Rio de Janeiro: Elsevier, 2003. p. Cap.28, p. 227-238.

AMARAL, D.C. O papel da gestão do conhecimento no processo de desenvolvimento de produtos. In: AMARAL, D.C. (org.) Gestão do ciclo de vida de produtos. Jaboticabal, SP: Editora Novos Talentos, 2005. Cap.18, p-261-281.

ANDRIOPOULOS, C. Determinants of organizational creativity: a literature review. Management Decision, v. 39, n.10, p.834-840, 2001.

BAUER, R.; MACEDO, T. M. B. Insights do pensamento complexo na construção de um modelo inovador em gestão do conhecimento. In: SIMPÓSIO DE GESTÃO DA INOVAÇÃO TECNOLÓGICA, 21, 2000, São Paulo. Anais... São Paulo: NPGT/USP, 2000.

BRAND, A. Knowledge management and innovation at 3M. Journal of Knowledge Management, Bingley - United Kingdom, vol. 2, no.1, p.17-22, 1998.

CANONGIA, C.; SANTOS, D.; SANTOS, M. M.; ZACKIEWICZ, M. Foresight, inteligência competitiva e gestão do conhecimento: instrumentos para a gestão da inovação. Gestão \& Produção, São Carlos, v. 11, n. 2, p.231-238, 2004.

CARVALHO, H. A. et al. Metodologia para implantação da gestão da qualidade de centros de pesquisa e desenvolvimento de instituições de ensino. In: SEMINARIO LATINO-IBEROAMERICANO DE GESTIÓN TECNOLÓGICA, 9, 2001, Costa Rica. Anais... Costa Rica: ENAMPAD, 2001. Disponível on-line: <http://www.lit. cpdtt.cefetpr.br/P_D/congressos.htm > Acesso em: 07 dez. 2004.

CERVO, A. L.; BERVIAN, P. A. Metodologia científica. 3.ed. São Paulo: McGraw-Hill, 1983.

CORDIS - Community Research \& Development Information Service. Contém informações sobre os projetos de pesquisa da comunidade européia, tais como editais, lista de projetos existentes e documentos sobre resultados de projetos passados. Disponível em:< http://cordis.europa.eu/>. Acesso em: 06 set. 2007.

DAVENPORT, T. H.; PRUSAK, L. Conhecimento empresarial: como as organizações gerenciam seu capital intelectual. Tradução de Lenke Peres. Rio de Janeiro: Campus, 1998.

DURAN, N.; AZEVEDO, M. M. M. Rede de pesquisa em nanobiotecnologia. Com Ciência. São Paulo, 2002. Disponível em: < http://www.comciencia.br/reportagens/nanotecnologia/ nano20.htm> Acesso em: 14 jan. 2005.

GARVIN, D. A. Construção da organização que aprende. In: Gestão do conhecimento - Harvard Business Review. Tradução Afonso Celso da Cunha Serra. Rio de Janeiro: Editora Campus, 2000. Publicado originalmente em Harvard Business Review, v.71, n.4, p.78-91, jul-aug, 1993.

GIL, A. C. Métodos e técnicas de pesquisa social. São Paulo: Atlas, 1999.

GONÇALVES, J. E. L. As empresas são grandes coleções de processo. Revista de administração de empresas, São Paulo, v.40, n.1, p.6-19, jan-mar 2000.

HAMEL, G.; PRAHALAD, C. K. Competindo pelo futuro: estratégias inovadoras para obter controle do seu setor e cria os mercados de amanhã. Tradução: Outras Palavras. 16 ed. Rio de Janeiro: Campus, 1995.

HUSTON, L.; SAKKAB, N. Connect and develop: inside Procter \& Gamble's new model for innovation. Harvar business review, n1, p.58-66, fevereiro, 2006

INSTITUTO FÁBRICA DO MILÊNIO. 2006. Disponível em: $<$ http://www.ifm.org.br>. Acesso em: 11 nov. 2006.

LATOUR, B.; WOOLGAR, S. A vida de laboratório: a produção dos fatos científicos. Tradução: Angela Ramalho Vianna. Rio de Janeiro: Relume Dumará, 1997.

LEONARD, D.; STRAUS, S. Aproveitando todo o cérebro da empresa. In: Gestão do conhecimento - Harvard Business Review. Tradução Afonso Celso da Cunha Serra. Rio de Janeiro: Editora Campus, 2000. Publicado originalmente em Harvard Business Review, v. 75, n. 4, p.110-121, jul-aug, 1997.

LIYANAGE, S.; GREENFIELD, P. F.; DON, R. Towards a fourth generation $\mathrm{R} \& \mathrm{D}$ management model-research networks in 
knowledge management. Int. J. Technology Management, v. 18, n. 3 - 4, p.372-393, 1999.

MACULAN, A.; FURTADO, C. Os pesquisadores e a transferência de conhecimento para a indústria. In: SIMPÓSIO DE INOVAÇÃO TECNOLÓGICA, 21, 2000, São Paulo, 7-10 nov. Anais... São Paulo: NPGT/USP, 2000.

MARCOVITCH, J.; BAIÃO, M. S. O Protap e a capacitação em C\&T: reflexões e experiências. São Paulo: CYTED/PGT/USP, 1999.

MOSCONI, E. P. Experiências de uma comunidade de prática sobre desenvolvimento de produtos: iniciativas e tecnologia promovendo aprendizagem e criação de conhecimentos. 148p. Dissertação - (Mestrado em Engenharia de Produção), Escola de Engenharia de São Carlos, Universidade de São Paulo, São Carlos, 2003.

MUNDIN, A. P. F. Cenário de integração do processo de desenvolvimento de produtos: uma pesquisa-ação em educação corporativa. São Carlos, 2001. 220p. Tese - (Doutorado em Engenharia Mecânica), Escola de Engenharia de São Carlos, Universidade de São Paulo.

NICKOLS, F. Comunitity of practice overview. 2000. Disponível em: $\quad<$ http://www.kmadvantage.com/docs/km_articles/ CoPOverview.pdf>. Acesso em: 26 nov. 2003.

NONAKA, I.; TAKEUCHI, H. Criação de conhecimento na empresa. Rio de Janeiro: Campus, 1997.

OLIVEIRA Jr., M. M. Competências essenciais e conhecimento na empresa. In: FLEURY, M. T. L.; OLIVEIRA Jr., M. M. Gestão estratégica do conhecimento: integrando aprendizagem, conhecimento e competências. São Paulo: Atlas, 2001. Cap. 4, p. 121-156.

REDESIST. 2004. Disponível em: <http://www.redesist.ie.ufrj.br> Acesso em: 14 jan. 2005.

RENAUX, D. P. B. et al. Gestão do conhecimento de um laboratório de pesquisa: uma abordagem prática. In: SIMPÓSIO INTERNACIONAL DE GESTÃO DO CONHECIMENTO/ GESTÃO DE DOCUMENTOS, 4, 2001, Curitiba. Anais... Curitiba: PUC-PR, 2001, p.195-208.

ROESCH, S. M. A. Projetos de estágio e de pesquisa em administração: guia para estágios, trabalhos de conclusão, dissertações e estudos de caso. 2 ed. São Paulo: Atlas, 1999.

SALABRIA, M. Knowledge leadership cycles: an approach from Nonaka's viewpoint. Journal of knowledge management, Bingley - United Kingdom, v.11, n.3, p.6-15, 2007.

SANTOS, G. J. A interfuncionalidade entre marketing e gestão de ciência e tecnologia nas empresas. Gestão \& Produção, São Carlos, v. 10, n. 3, p.329-344, 2003.
SATO, G. Y. Gestão do conhecimento aplicada na integração de estagiários novatos no núcleo de pesquisa em engenharia simultânea do CEFET-PR: diagnóstico e recomendações. Curitiba, 2001. 196p. Dissertação (Mestrado em Tecnologia), Centro Federal de Educação Tecnológica do Paraná.

SENGE, P. M. A quinta disciplina: Arte, teoria e prática da organização de aprendizagem. São Paulo: Best Seller, 1990.

SENGE, P. M.; KÄUFER, K. H. Comunidades de líderes ou ausência de liderança. In: CHOWDHURY, S. Administração do século XXI: o modo de gerenciar hoje e no futuro. Tradução de Maria Lúcia G. L. Rosa. Revisão Técnica de Carlos A. Caldas Moraes. São Paulo: Pearson Education do Brasil. Cap. 14, p. 185-204, 2003.

SILVA, E. V.; MOSCONI, E. P.; SILVA, S. Experiências em gestão do conhecimento em um grupo de pesquisa multidisciplinar sobre desenvolvimento de produtos. In: INTERNATIONAL SYMPOSIUM ON KNOWLEDGE MANAGEMENT, 6, 2003, Curitiba. Anais... Curitiba: CITS, 2003. (CD-ROM).

SILVA, S. L. Proposição de um modelo para caracterização das conversões do conhecimento no processo de desenvolvimento de produtos. São Carlos, 2002. 216p. Tese - (Doutorado em Engenharia Mecânica), Escola de Engenharia de São Carlos, Universidade de São Paulo.

SOUZA, Y. S. Organizações de aprendizagem ou aprendizagem organizacional. RAE-Eletrônica, São Paulo, v.3, n.1, p.1-16, jan-jun. Disponível em: <http://www.rae.com.br/eletronica/index. cfm?FuseAction $=$ Artigo $\& I D=1812 \&$ Secao $=$ ORGANIZA\&Volu $m e=3 \&$ Numero $=1 \& A n o=2004>$. Acesso em: 01 abr. 2004.

STRAUHS, F. R.; ABREU, A. F.; RENAUX, D. F. B. Uma proposta para gestão do conhecimento em laboratório acadêmico. In: SIMPÓSIO INTERNACIONAL DE GESTÃO DO CONHECIMENTO/GESTÃO DE DOCUMENTOS, 3, 2000, Curitiba. Anais... Curitiba: PUC-PR. 2000, p.17-36.

Laboratório de ensino, pesquisa e desenvolvimento como organizações de aprendizagem: um estudo de caso. In: SIMPÓSIO DE GESTÃO DA INOVAÇÃO TECNOLÓGICA, 22, 2002, Salvador. Anais... São Paulo: NPGT/USP, 2002.

TERRA, J. C. C. Gestão do conhecimento: aspectos conceituais e estudo exploratório sobre as práticas de empresas brasileiras. In: FLEURY, M. T. L.; OLIVEIRA Jr., M. M. Gestão estratégica do conhecimento: integrando aprendizagem, conhecimento e competências. São Paulo: Atlas, 2001. Cap. 7, p. 212-241.

YIN, R. K. Case study research: design and methods. 2 ed. Londres: Sage Publications, 1994.

ZARIFIAN, P. Objetivo competência: por uma nova lógica. Tradução de Maria Helena V. V. Trylinski. São Paulo: Atlas, 2001.

\section{Sobre os autores}

\section{Karina Kühl de Lima \\ Daniel Capaldo Amaral}

Grupo de Engenharia Integrada, Departamento de Engenharia de Produção, Escola de Engenharia de São Carlos - EESC, Universidade de São Paulo - USP, Av. Trabalhador São-carlense, 400, CEP 13566-590, São Carlos, SP, Brasil, e-mails: karinaklima@yahoo.com.br; amaral@sc.usp.br

Agradecimentos: Os autores agradecem a todos os pesquisadores da rede IFM pela colaboração e aos revisores anônimos pelo excelente trabalho, que permitiu um avanço significativo no texto final. Esta pesquisa contou com o apoio do MCT, Capes, CNPq e do Programa Institutos do Milênio. 